\title{
Achieving Escape Velocity: Neighborhood and School Interventions to Reduce Persistent Inequality
}

\section{Citation}

Fryer, Roland G, and Lawrence F Katz. 2013. Achieving Escape Velocity: Neighborhood and School Interventions to Reduce Persistent Inequality. American Economic Review 103, no. 3 : 232-237.

\section{Published Version}

doi:10.1257/aer.103.3.232

\section{Permanent link}

http://nrs.harvard.edu/urn-3:HUL.InstRepos:12330898

\section{Terms of Use}

This article was downloaded from Harvard University's DASH repository, and is made available under the terms and conditions applicable to Open Access Policy Articles, as set forth at http:// nrs.harvard.edu/urn-3:HUL.InstRepos:dash.current.terms-of-use\#OAP

\section{Share Your Story}

The Harvard community has made this article openly available.

Please share how this access benefits you. Submit a story.

\section{Accessibility}




\title{
ACHIEVING Escape VELOCITY: NeIGHBORHOOD AND SCHOOL INTERVENTIONS TO Reduce Persistent IneQuality
}

\author{
By Roland G. Fryer, JR. AND LAWRENCE F. KATZ *
}

\begin{abstract}
* Fryer: Department of Economics, Harvard University, Cambridge MA 02138 and National Bureau of Economic Research (email: rfyrer@fas.harvard.edu); Katz: Department of Economics, Harvard University, Cambridge MA 02138 and National Bureau of Economic Research (email: lkatz@harvard.edu). We are grateful to the Broad Foundation, Ford Foundation, the National Institute of Child and Health Development (R01-HD040404), and the National Institute of Mental Health (R01-MH077026) for financial support; Matt Davis, Blake Heller, Nicholas Potter, and Matt Sciandra for exceptional research assistance; and Greg Duncan and Jens Ludwig for comments..
\end{abstract}

Nearly fifty years after the Civil Rights Act of 1964, racial inequality in America remains a persistent empirical regularity. Despite much progress in the 1960s and 1970s, large adverse black-white gaps persist in earnings, employment, family income, health, life expectancy, incarceration, teen pregnancy, educational attainment, and academic achievement. Hispanic-white gaps in economic and educational outcomes also remain substantial (Fryer 2011).

Minority children from low-income families residing in high-poverty (and increasingly economically-isolated) neighborhoods appear to be particularly disadvantaged. For example, Figure 1 shows a strong positive correlation between mean residential neighborhood (zip code) income and the academic performance of 8th grade students in New York City for 2009-10. This correlation could reflect the causal effects of direct neighborhood characteristics, school quality differences by neighborhood, or family background factors.

\section{[Insert Figure 1 About Here]}

A key policy question is whether highquality schools alone can weaken the cycle of intergenerational poverty for those growing up in high-poverty areas or whether broader neighborhood-based interventions are necessary or sufficient to achieve this aim. ${ }^{1}$ An ideal randomized experiment would contrast a treatment of improving neighborhood quality while keeping school quality constant to one of improving school quality while leaving the neighborhood unchanged to one that improved both neighborhood and school quality. Although no such study exists, there is a growing body of evidence using credible experimental and quasi-experimental sources of variation in

\footnotetext{
${ }^{1}$ Other approaches include policies to improve parenting practices and to increase family resources.
} 
neighborhoods and schools. We examine this literature, using a simple conceptual framework, to shed light on which interventions may achieve escape velocity for disadvantaged children - allowing youth to escape the gravitational pull of poverty.

\section{Conceptual Framework}

To aid in interpreting the reduced form estimates in the literature, we use a simple model of production. Let outcome $e^{j}$ denote a representative outcome $j$, where $j$ might represent physical health, mental health, human capital, and risky behaviors. For each $j$, we assume a simple production process: outcome $e^{j}=f^{j}(\eta, \sigma, \phi)$, where $\eta$ represents neighborhood quality, $\sigma$ denotes school quality, and $\phi$ captures family background. We assume that $f$ is smooth and twice continuously differentiable in its arguments. ${ }^{2}$

Imagine that the outcome of interest is mental health and we want to understand the impact of important changes in neighborhood quality on this outcome holding school quality and family background fixed. This is equivalent to estimating $\frac{\partial f^{\text {health }}}{\partial \eta}$. On the other hand, one may want to understand the impact of investments in K-12 education reform on

\footnotetext{
2 In a more general functional form, one could allow there to be other direct and indirect effects of inputs on outputs.
}

human capital holding neighborhood quality and family background fixed by estimating $\frac{\partial f^{\text {human capital }}}{\partial \sigma}$.

In some cases, such as the Harlem Children's Zone (HCZ), interventions can change both neighborhood and school quality. However, Dobbie and Fryer (2011) argue that students who live outside the boundaries of the HCZ, making them less likely to reap the benefits of neighborhood investments, garner the same test score gains from HCZ's Promise Academy charter school as do students inside the zone. Students living out of the zone get better schools with no change in neighborhood quality or family background $\left(\frac{\partial f^{j}}{\partial \sigma}\right)$. Students living in the zone who attend the Promise Academy (relative to students in the Zone who do not attend the schools) get $\frac{\partial f^{j}}{\partial \sigma}+\frac{\partial f^{2^{j}}}{\partial \sigma \partial \eta}$. If these two estimates are similar, it implies that the interaction term is trivial.

\section{Neighborhoods}

The Moving to Opportunity (MTO) randomized housing mobility experiment provides substantial exogenous variation in the neighborhood environments facing lowincome families. ${ }^{3}$ From 1994 to 1998, MTO

\footnotetext{
3 Credible quasi-experimental studies of neighborhood effects include Oreopoulos (2003) or Jacob (2004).
} 
enrolled 4,604 poor families with children residing in public housing in high-poverty neighborhoods of Baltimore, Boston, Chicago, Los Angeles, and New York City. Families were randomly assigned to three groups: (1) the Experimental voucher group, which received a restricted housing voucher that could be used to pay for private rental housing initially restricted to be in a low-poverty area (a census tract with under a 10 percent poverty rate in 1990) and housing-mobility counseling; (2) the Section-8 only voucher group, which received regular Section 8 housing vouchers with no MTO relocation constraint; and (3) a control group, which received no assistance through MTO.

Across the MTO treatment sites, 61 percent of household heads were non-Hispanic blacks, 31 percent were Hispanic, and nearly all households were female-headed at baseline. About half of the Experimental group and 63 percent of the Section 8-only group were able to lease up and move with an MTO voucher (the compliance rate). The MTO families were tracked for 15 years using administrative data as well as major interim (4 to 7 years after random assignment) and long-term (10 to 15 years after random assignment) follow-up surveys and analyses (Kling, Liebman, and Katz 2007; Sanbonmatsu et al. 2011).
MTO generated large and persistent improvements in residential neighborhoods for the treatment groups (especially the Experimental group) relative to the control group but only modest changes in school quality (as seen in Appendix Table 1). The average MTO family lived at baseline in a neighborhood with a 53 percent poverty rate. MTO led to a 9 percentage point decline in the duration-weighted average tract poverty rate over the 10-15 year follow-up period for the Experimental group relative to the control group and a 19 percentage point decline for Experimental compliers (those who moved with an MTO voucher).

In stark contrast, MTO only modestly improved school quality for the MTO treatment groups. From the time of random assignment until the long-term follow-up, Experimental group children attended schools that outranked their control group peers' by only 3 percentile points on state exams, and Section-8 only group children attended schools that performed just 1 percentile point higher. MTO treatment group students also typically remained in schools where the majority of the students were low-income and minority. MTO reduced the share of students eligible for free or reduced-price lunch by 4 percentage points for the Experimental group. 
Although it is difficult to compare the size of neighborhood quality change to that of school quality change, MTO appears to have improved neighborhood quality by substantially more. The MTO treatment groups experienced more than twice as large a reduction in the share of poor residential peers as compared to poor school peers and more than three times as large an improvement in percentile rank in the national Census-tract poverty distribution for their neighborhoods than in the state test score distribution for their schools. Many of the MTO movers remained in the same school districts and very similar schools. MTO also had no significant impact on adult economic self-sufficiency or family income at the interim or long-run follow-ups. Thus, an analysis of the impacts of MTO treatments on child outcomes comes close to getting at the pure effects of changes in neighborhood conditions for disadvantaged kids (with little change in schools or family economic resources): $\frac{\partial f^{j}}{\partial \eta}$ in our framework.

The MTO voucher treatments did not detectably impact parent's economic outcomes, but they did significantly and persistently improve key aspects of mother's (adult female's) mental and physical health including substantial reductions in psychological distress, extreme obesity, and diabetes (Ludwig et al. 2011; Sanbonmatsu et al. 2011). MTO movers also experienced significant increases in adult subjective wellbeing with larger gains for adults from sites where treatment induced larger reductions in neighborhood poverty (Ludwig et al. 2012). For female youth, MTO treatments similarly led to persistent and significant improvements in mental health (including substantial reductions in psychological distress) and marginally significant improvements in physical health, but there were no long-term detectable health impacts for male youth (Kling, Liebman and Katz 2007; Sanbonmatsu et al. 2011.)

Interestingly, MTO produced no sustained improvements in academic achievement, educational attainment, risky behaviors, or labor market outcomes for either female or male children, including those that were below school age at the time of random assignment. Furthermore, the variation across sites in the degree of changes in neighborhood quality induced by treatment generates no detectable long-term relationship between changes in neighborhood poverty and youth educational outcomes or risky behaviors. ${ }^{4}$

\footnotetext{
${ }^{4}$ There is variation across MTO sites in changes in school quality by treatment group as seen in state test score percentile rankings and MTO children's selfreports of school climate. These data demonstrate a positive (but typically not statistically significant) relationship between MTO treatment group educational and risky behavior outcomes and mean gains in school
} 
The MTO findings imply that even large improvements in neighborhood conditions for poor families (in the range feasible with Section 8 vouchers) that do not do not also lead large improvements in school quality do not produce noticeable gains in children's economic and educational outcomes $\left(\frac{\partial f^{\text {human capital }}}{\partial \eta} \approx 0\right)$ but can improve girl's health $\left(\frac{\partial f^{\text {health }}}{\partial \eta}>0\right.$ for females). Variation across sites in the school quality changes induced by treatment is suggestive of a key role for schools in children's human capital outcomes and risky behaviors.

\section{Schools}

The MTO experiment produced large exogenous changes in neighborhoods and small changes in schools - an example of altering neighborhoods while holding schools fixed. In this section, we briefly describe alternative research designs in which important elements of the educational production function were changed, while neighborhoods remained constant. In our framework, this is equivalent to $\frac{\partial f^{j}}{\partial \sigma}$ for outcomes $j$. We conclude by examining the Harlem Children's Zone, a social experiment

quality that is stronger for males than females (Appendix Figures 1 to 4). designed to increase both neighborhood and school quality, which provides estimates of the different components of the total derivative: $\frac{\partial f^{j}}{\partial \sigma}+\frac{\partial f^{j}}{\partial \eta}+\frac{\partial f^{2^{j}}}{\partial \sigma \partial \eta}$.

Using data from Project STAR - an experiment carried out in 79 Tennessee schools from 1985 to 1989 where 11,571 students in grades $\mathrm{K}$ to 3 were randomly assigned to small classes averaging 15 students or regular classes averaging 22 students - Chetty et al. (2011) estimate the impact of reduced class size on young adult educational and economic outcomes by linking students from Project STAR to individual and administrative tax records collected by the U.S. Internal Revenue Service. They find positive effects of being randomly assigned to a smaller class size in early grades on college attendance and a summary index of adult outcomes designed to broadly capture socioeconomic success in young adulthood.

Similarly, Fredriksson, Öckert, and Oosterbeek (2013) use a regressiondiscontinuity design that exploits a maximum class size rule to examine the effects of attending smaller classes in primary grades. Using rich administrative data from Sweden, they find substantial and statistically significant positive effects on educational 
attainment, adult wages, and earnings at ages 27 to 42 years. In symbols, $\frac{\partial f^{j}}{\partial \sigma}>0$ for outcomes such as college attendance, earnings, and other adult economic outcomes when school quality is measured as a reduction in class size while holding teacher quality constant.

Good teachers also seem to matter. To test the causal impact of high value-added (VA) teachers on medium-term outcomes such as college attendance, earnings, and teen pregnancy, Chetty, Friedman, and Rockoff (2011) link individual-level student achievement data on over 2 million students in a large U.S. urban school district to administrative tax data on the students' parental characteristics and adult outcomes. They use a quasi-experimental research design exploiting changes in teaching staff. Students assigned to a high-VA teacher in grades 4 to 8 earn more at age 28 , are less likely to be teen parents, and are more likely enroll in college or attend a high-quality college.

The Harlem Children's Zone is a 97-block area in Harlem, New York, that combines "No Excuses" charter schools with neighborhood services designed to ensure the social environment outside of school is positive and supportive for children from birth to college graduation. ${ }^{5}$ HCZ was created to address all the problems that poor children in Harlem face - housing, schools, crime, asthma, and so on through a "conveyor belt" of services from birth to college. The approach is based on the assumption that one must improve both neighborhoods and schools to affect student achievement (Dobbie and Fryer 2011).

Dobbie and Fryer (2012) use the randomassignment nature of lottery admissions to determine the causal effect of being offered admission to the HCZ Promise Academy charter school on academic achievement and medium-term life outcomes. Because many of the students admitted to the HCZ schools live outside the boundary of HCZ neighborhood supports, comparing student outcomes and Promise Academy lottery-based treatment effect estimates for those who live inside the zone with those who live outside the zone can help separate out the impacts of schools, neighborhoods, and their interaction on youth outcomes.

To analyze the impact of attending the charter schools in HCZ on medium-term life outcomes, Dobbie and Fryer (2012) survey the middle school lottery cohorts six to seven years after the initial lottery and link

\footnotetext{
5 "No Excuses" schools typically allow the principal considerable administrative freedom, set measurable goals that are regularly tested using interim assessments, emphasize parent participation, and create a culture of universal achievement that make no excuses based on the students' background.
} 
administrative data to the New York City Department of Education and National Student Clearinghouse records. Dobbie and Fryer (2012) find that lottery winners have large and significant increases in math performance and marginal improvements in reading, and are 14.1 percentage points more likely to enroll in college. Female lottery winners are 12.1 percentage points less likely to be teen mothers, and male lottery winners are 4.3 percentage points less likely to be incarcerated. Creating indices for human capital, risky behaviors, and health, Dobbie and Fryer (2012) report large and significant increases in human capital, large and marginally significant decreases in risky behaviors, and no observable impact on health outcomes. These HCZ results, summarized in Appendix Figure 5, stand in direct contrast to the results from the MTO neighborhood intervention, where positive female health effects were paired with null results on youth human capital and risky behavior.

A key issue for understanding the HCZ results within our framework concerns distilling the independent effects of the HCZ neighborhood supports in addition to improvements in school quality. To do this, Dobbie and Fryer (2012) examine differential treatment effects based upon how far from the boundaries of HCZ a student lives. Comparing lottery winners outside the zone to lottery losers outside the zone provides an estimate of pure school quality effects $\left(\frac{\partial f^{j}}{\partial \sigma}\right)$ for individuals exposed to HCZ's charter schools but not its neighborhood programs (normalizing $\eta=0$ for the out of zone group). For this group, Dobbie and Fryer report large positive treatment effects on an index of human capital outcomes, marginally significant reductions in risky behaviors, and no impacts on physical or mental health.

Comparing lottery winners within the zone to lottery losers in the zone yields an estimate of $\frac{\partial f^{j}}{\partial \sigma}+\frac{\partial f^{2^{j}}}{\partial \sigma \partial \eta}$. Dobbie and Fryer (2012) estimate that in only one out of thirteen outcomes (number of advanced high school exams passed) is the treatment effect of gaining access to the Promise Academy for those in the zone $\left(\frac{\partial f^{j}}{\partial \sigma}+\frac{\partial f^{2^{j}}}{\partial \sigma \partial \eta}\right)$ larger than that for those out of the zone $\left(\frac{\partial f^{j}}{\partial \sigma}\right)$. These findings imply that for the outcomes analyzed there is no important interaction of neighborhood and school quality $\left(\frac{\partial f^{2 j}}{\partial \sigma \partial \eta} \approx 0\right.$ ). If one restricts attention to the three main outcome indices (human capital, risky behavior, and health), the interaction term effectively is zero.

Finally, comparing lottery losers outside the zone to lottery losers inside the zone provides 
an estimate of neighborhood effects $\left(\frac{\partial f^{j}}{\partial \eta}\right)$. Across all three outcome indices, the estimates are zero though imprecisely measured. The MTO experiment provides a better laboratory for estimating $\frac{\partial f^{j}}{\partial \eta}$, indicating little neighborhood quality impacts on human capital and risky behavior outcomes but substantial health impacts for females.

\section{Conclusions}

The estimates reviewed provide some guidance as to how neighborhoods and schools enter the production functions for children's medium-term outcomes in the domains of human capital, risky behaviors, and health. The evidence suggests that investments in school quality are more effective in decreasing persistent economic and educational inequalities and for reducing risky behaviors. Neighborhood improvements, however, do more to reduce mental and physical health inequalities. With sufficient budgetary resources, policy-makers would try to improve both neighborhood and school quality for low-income children. However, in the face of increasingly stringent budgetary limits, policy-makers face trade-offs and it is important to choose appropriate instruments for the outcomes one wants to affect. A vital policy question is how to generate systematic large-scale improvements in school and teacher quality for low-income students growing up in high-poverty neighborhoods.

\section{REFERENCES}

Chetty, Raj, John N. Friedman, Nathaniel Hilger, Emmanuel Saez, Diane W. Schanzenbach, and Danny Yagan. 2011. "How Does Your Kindergarten Classroom Affect Your Earnings? Evidence from Project Star." Quarterly Journal of Economics 126 (4): 1593-1660.

Chetty, Raj, John N. Friedman, and Jonah E. Rockoff. 2011. “The Long-Term Impact of Teachers: Teacher Value-Added and Student Outcomes in Adulthood.” NBER Working Paper No. 17699, December.

Dobbie, Will and Roland G. Fryer, Jr. 2011. “Are High-Quality Schools Enough to Increase Achievement among the Poor? Evidence from the Harlem Children's Zone." American Economic Journal: Applied Economics 3 (3): 158-87.

Dobbie, Will and Roland G. Fryer, Jr. 2012. "Are High-Quality Schools Enough to Reduce Social Disparities? Evidence from the Harlem Children’s Zone?” Unpublished. Fredriksson, Peter, Björn Öckert, and Hessel Oosterbeek. 2013. "Long-Term Effects of Class Size.” Quarterly Journal of Economics 128 (1), forthcoming. 
Fryer, Roland G. 2011. "Racial Inequality in the 21st Century: The Decline Significance of Discrimination." In Handbook of Labor Economics Volume 4B, eds. Orley Ashenfelter and David Card, 855-971. Amsterdam: North Holland.

Jacob, Brian A. 2004. "Public Housing, Housing Vouchers, and Student Achievement: Evidence from Public Housing Demolitions in Chicago.” American Economic Review 94(1): 233-58.

Kling, Jeffrey R., Jeffrey B. Liebman, and Lawrence F. Katz. 2007. “Experimental Analysis of Neighborhood Effects.” Econometrica 75 (1): 83-119.

Ludwig, Jens, Greg J. Duncan, Lisa A. Gennetian, Lawrence F. Katz, Ronald C. Kessler, Jeffrey R. Kling, and Lisa Sanbonmatsu. 2012. "Neighborhood Effects on the Long-Term Well-Being of LowIncome Adults.” Science 337 (6101): 15051510.

Ludwig, Jens, Lisa Sanbonmatsu, Lisa Gennetian, Emma Adam, Greg J. Duncan, Lawrence F. Katz, Ronald C. Kessler, et al. 2011. "Neighborhoods, Obesity, and Diabetes - a Randomized Social Experiment." The New England Journal of Medicine 365 (16): 1509-19.

Oreopoulos, Philip. 2003. “The Long-run Consequences of Growing Up in a Poor
Neighborhood." Quarterly Journal of Economics 118(4): 1533 -575.

Sanbonmatsu, Lisa, Jens Ludwig, Lawrence F. Katz, Lisa A. Gennetian, Greg J. Duncan, Ronald C. Kessler, Emma Adam, Thomas W. McDade, and Stacy Tessler Lindau. 2011. Moving to Opportunity for Fair Housing Demonstration Program: Final Impacts Evaluation. Washington, DC. www.huduser.org/publications/pdf/MTOFH D_fullreport_v2.pdf. 


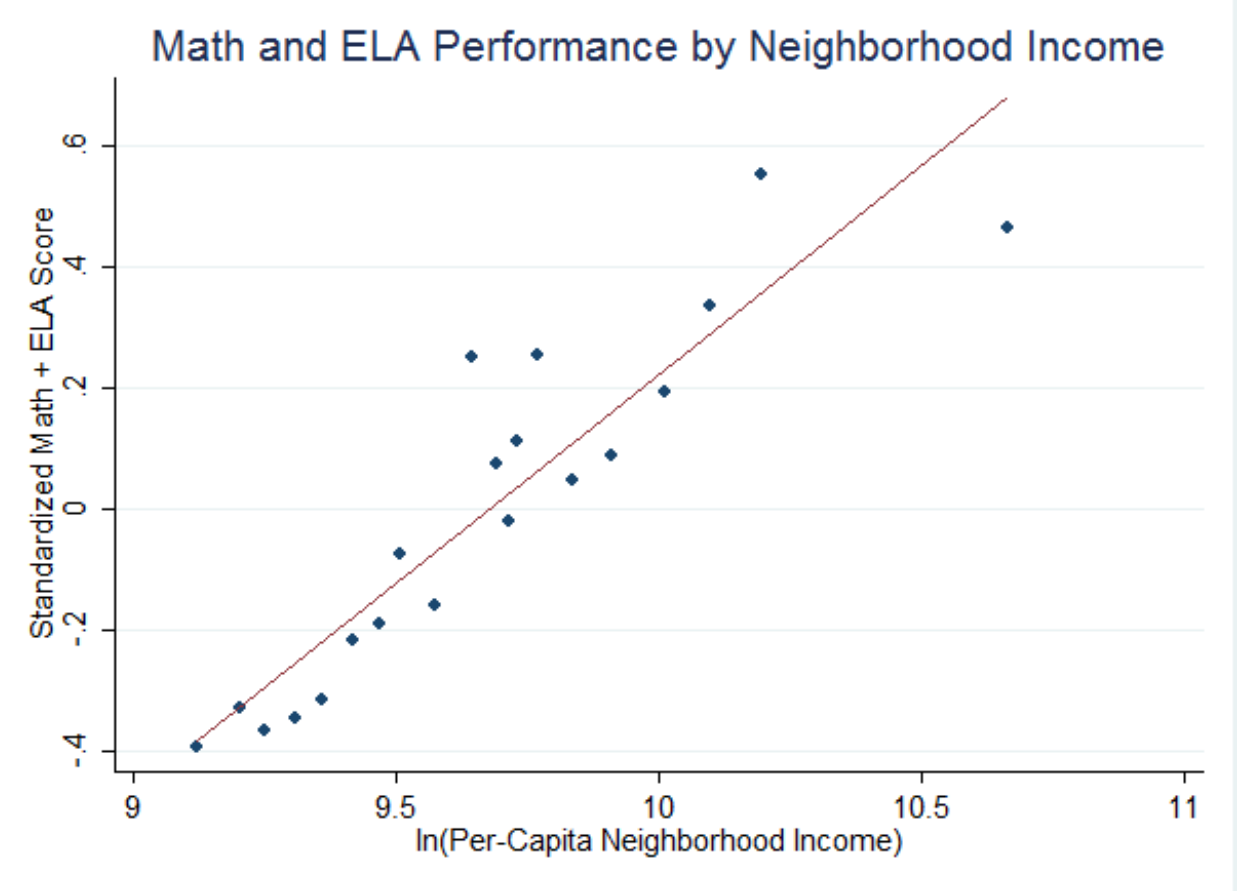

FIGURE 1. EIGHTH GRADE MATH AND ELA PERFORMANCE BY NEW YORK CITY NEIGHBORHOOD INCOME

Note: The figure plots mean 8th grade standardized New York State Math and English Language Arts (ELA) achievement test scores of resident students against ln(neighborhood per-capita income) for twenty equal sized (5 percentile point) bins of neighborhood (zip code) per-capita income. The solid line shows OLS estimates for the underlying student-level data. Math and ELA test score is constructed by summing test-bygrade specific scale scores from New York City Department of Education administrative data and standardizing the sum for the NYC 8th grade sample. Neighborhood is the zip code of a student's primary residence. Zip code per-capita income is from the 2000 Census of Population. 


\title{
On-Line Appendix
}

\section{“Achieving Escape Velocity: Neighborhood and Social Interventions to Reduce Persistent Inequality”}

\author{
Roland G. Fryer, Jr. and Lawrence F. Katz \\ Harvard University and NBER
}

January 2013 
Appendix Table 1

MTO Impacts on Neighborhood and School Quality

\begin{tabular}{|c|c|c|c|c|c|c|}
\hline & \multirow[b]{2}{*}{$\begin{array}{c}\text { Control } \\
\text { mean }\end{array}$} & \multicolumn{2}{|c|}{$\begin{array}{l}\text { Experimental versus } \\
\text { Control }\end{array}$} & \multicolumn{2}{|c|}{$\begin{array}{l}\text { Section } 8 \text { versus } \\
\text { Control }\end{array}$} & \multirow[b]{2}{*}{$\begin{array}{l}\text { Sample } \\
\text { Size }\end{array}$} \\
\hline & & ITT & TOT & ITT & TOT & \\
\hline \multicolumn{7}{|l|}{ A. Neighborhood Quality } \\
\hline \multicolumn{7}{|l|}{$\begin{array}{l}\text { Average Census Tract Poverty } \\
\text { Rate, MTO Youth }\end{array}$} \\
\hline Share Poor & 0.399 & $\begin{array}{l}-0.090 \\
(0.007)\end{array}$ & $\begin{array}{l}-0.188 \\
(0.013)\end{array}$ & $\begin{array}{l}-0.076 \\
(0.007)\end{array}$ & $\begin{array}{l}-0.113 \\
(0.010)\end{array}$ & 4,637 \\
\hline $\begin{array}{l}\text { Share Poor, percentile units } \\
\text { among U.S. tracts }\end{array}$ & 91.85 & $\begin{array}{l}-8.87 \\
(0.64)\end{array}$ & $\begin{array}{l}-18.38 \\
(1.09)\end{array}$ & $\begin{array}{l}-4.63 \\
(0.53)\end{array}$ & $\begin{array}{l}-6.90 \\
(0.76)\end{array}$ & 4,637 \\
\hline $\begin{array}{l}\text { Share Poor, z-score on U.S. } \\
\text { tracts }\end{array}$ & 2.102 & $\begin{array}{l}-0.733 \\
(0.057)\end{array}$ & $\begin{array}{l}-1.520 \\
(0.102)\end{array}$ & $\begin{array}{l}-0.613 \\
(0.056)\end{array}$ & $\begin{array}{l}-0.914 \\
(0.079)\end{array}$ & 4,637 \\
\hline \multicolumn{7}{|l|}{$\begin{array}{l}\text { B. School Quality for } \\
\text { Average School Attended }\end{array}$} \\
\hline $\begin{array}{l}\text { Share Eligible for Free- or } \\
\text { Reduced-Price Lunch }\end{array}$ & 0.752 & $\begin{array}{l}-0.040 \\
(0.007)\end{array}$ & $\begin{array}{r}-0.083 \\
(0.014)\end{array}$ & $\begin{array}{l}-0.019 \\
(0.008)\end{array}$ & $\begin{array}{l}-0.029 \\
(0.012)\end{array}$ & 5,043 \\
\hline $\begin{array}{l}\text { School Percentile Ranking on } \\
\text { State Exam }\end{array}$ & 18.68 & $\begin{array}{c}3.07 \\
(0.65)\end{array}$ & $\begin{array}{c}6.43 \\
(1.36)\end{array}$ & $\begin{array}{c}1.22 \\
(0.66)\end{array}$ & $\begin{array}{c}1.81 \\
(0.98)\end{array}$ & 4,884 \\
\hline School Climate Index, All & 0.797 & $\begin{array}{c}0.020 \\
(0.011)\end{array}$ & $\begin{array}{c}0.043 \\
(0.023)\end{array}$ & $\begin{array}{l}-0.002 \\
(0.012)\end{array}$ & $\begin{array}{l}-0.003 \\
(0.017)\end{array}$ & 3.328 \\
\hline School Climate Index, Female & 0.786 & $\begin{array}{c}0.025 \\
(0.015)\end{array}$ & $\begin{array}{c}0.052 \\
(0.032)\end{array}$ & $\begin{array}{c}0.006 \\
(0.016)\end{array}$ & $\begin{array}{c}0.010 \\
(0.025)\end{array}$ & 1,694 \\
\hline School Climate Index, Male & 0.807 & $\begin{array}{c}0.016 \\
(0.014)\end{array}$ & $\begin{array}{c}0.034 \\
(0.031)\end{array}$ & $\begin{array}{l}-0.011 \\
(0.016)\end{array}$ & $\begin{array}{l}-0015 \\
(0.022)\end{array}$ & 1,634 \\
\hline
\end{tabular}

Notes and Sources: ITT are intent-to-treat estimates; TOT are treatment-on-treated estimates. Panel A presents the control group mean, ITT, and TOT estimates for average (duration-weighted) neighborhood (census tract) poverty rates in raw units, percentile units, and standardized (z-score) units for MTO youth ages 13-20 (as of December 2007) for all post-random assignment residential addresses. Census tract poverty rates in each year are interpolated using the 1990 Census, 2000 Census, and the 2005-09 American Community Surveys. Panel B present (duration-weighted) average characteristics for the schools attended by MTO youth ages 10-20 (with the school climate index covering youth ages 10 to 17). The School Climate Index is share of positive responses to five school climate questions: students get teased if they study hard, discipline in school is fair, feels safe in school, often feels put down by teachers, and teacher interested in students. The source for Panel B is Sanbonmatsu et al. (2011), Exhibits 7.3 and 7.5. 


\section{Appendix Figure 1}

\section{Instrumental Variable Estimation of the Relationship between Educational Attainment and School Climate}

A FEMALE YOUTH: Educational Attainment vs. School Climate

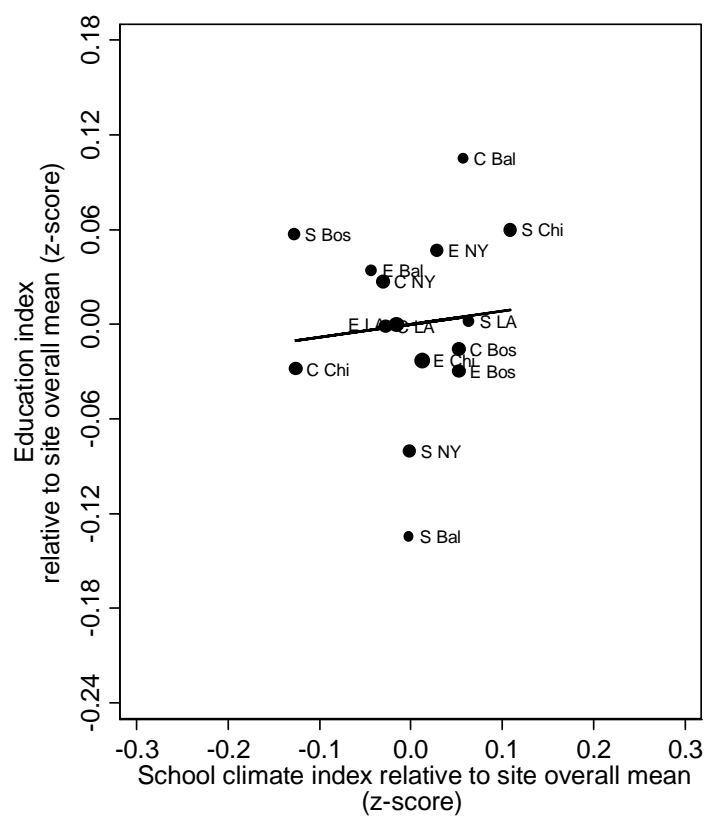

C

FEMALE YOUTH: Educational Attainment vs. School Climate Controlling for Poverty

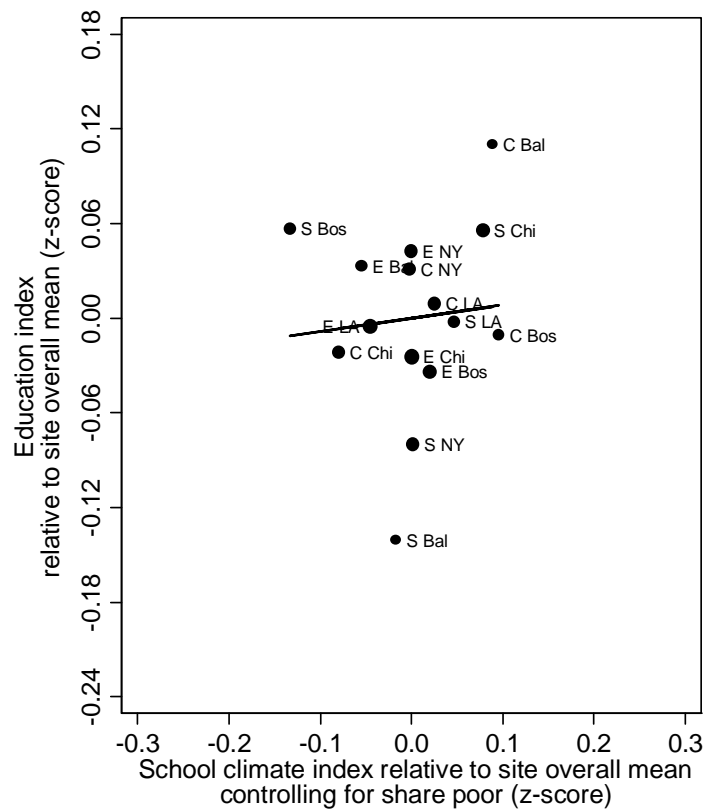

MALE YOUTH: Educational Attainment vs. School Climate

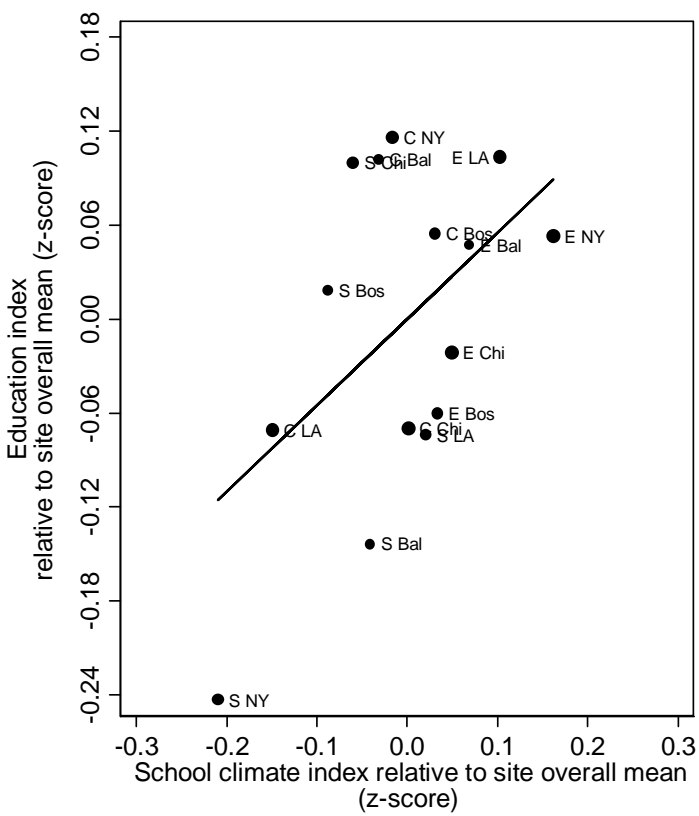

D MALE YOUTH: Educational Attainment vs. School Climate Controlling for Poverty

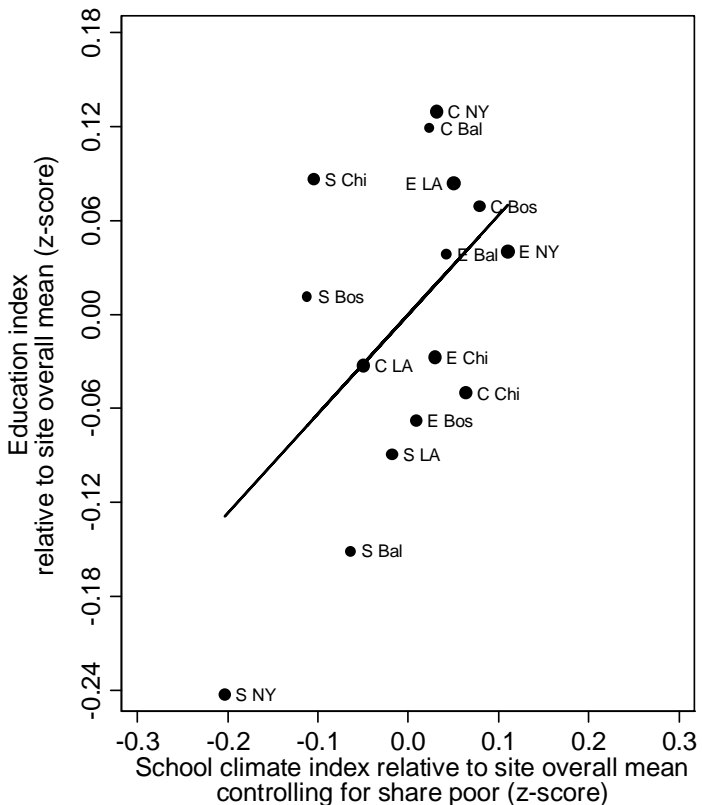


Notes to Appendix Figure 1: Instrumental variable estimation of the relationship between educational attainment and school climate for females (Panel A) and males (Panel B) and school climate controlling for poverty for females (Panel C) and males (Panel D). The y-axis is the education index expressed in standard deviation units relative to the sample control group standard deviation. The index has the following components: graduated high school/received certificate of General Educational Development (GED) or still in school, in school or working, ECLS-K reading score, and ECLS-K math score. Each component was standardized using the mean and standard deviation for the control group. The index is the average of its components, restandardized using the control mean and standard deviation after averaging. Negative components were flipped so that higher index values represent "better" outcomes. School climate is the ratio of positive responses on five school quality items: safety, discipline, feeling "put down" by teachers, teasing of students who study hard, and teacher interest in students. Poverty (share poor), controlled for in panels $\mathrm{C}$ and $\mathrm{D}$, is the fraction of census tract residents living below the poverty threshold, linearly interpolated from the 1990 and 2000 decennial census and 2005-09 American Community Survey and weighted by the amount of time respondents lived at each of their addresses from random assignment through May 2008. School climate and share poor are expressed as z-scores standardized by the control group mean and standard deviation. The points represent the site $(\mathrm{Bal}=$ Baltimore, Bos = Boston, Chi $=$ Chicago, LA = Los Angeles, NY = New York City) and treatment group ( $\mathrm{E}=$ Experimental voucher, $\mathrm{S}=$ Section 8 voucher, $\mathrm{C}$ = control group). The line through the data points is equivalent to a two-stage least-squares estimate of the relationship between educational attainment and school climate, using site-group interactions as instruments (conditional on site main effects). The size of each point is proportional to the sum of the weights for that group and, correspondingly, to the weight that the point receives in the two-stage least squares regression. The estimated impact of a 1 standard deviation (sd) improvement in school climate is a 0.082sd increase in educational attainment for females (Panel A; N=2367, SE=0.432, $\mathrm{P}=0.849$ ) and a 0.550sd increase for males (Panel B; $\mathrm{N}=2271, \mathrm{SE}=0.241$, $\mathrm{P}=0.022)$. When controlling for poverty, the estimated impact of a 1sd improvement in school climate is a 0.084 sd increase in educational attainment for females (Panel C; $\mathrm{N}=2364, \mathrm{SE}=0.454, \mathrm{P}=0.852$ ), and a 0.633sd increase for males (Panel D; $\mathrm{N}=2267, \mathrm{SE}=0.315, \mathrm{P}=0.044$ ). 


\section{Appendix Figure 2}

\section{Instrumental Variable Estimation of the Relationship between Risky Behavior and School Climate}

A

FEMALE YOUTH: Risky Behavior vs. School Climate

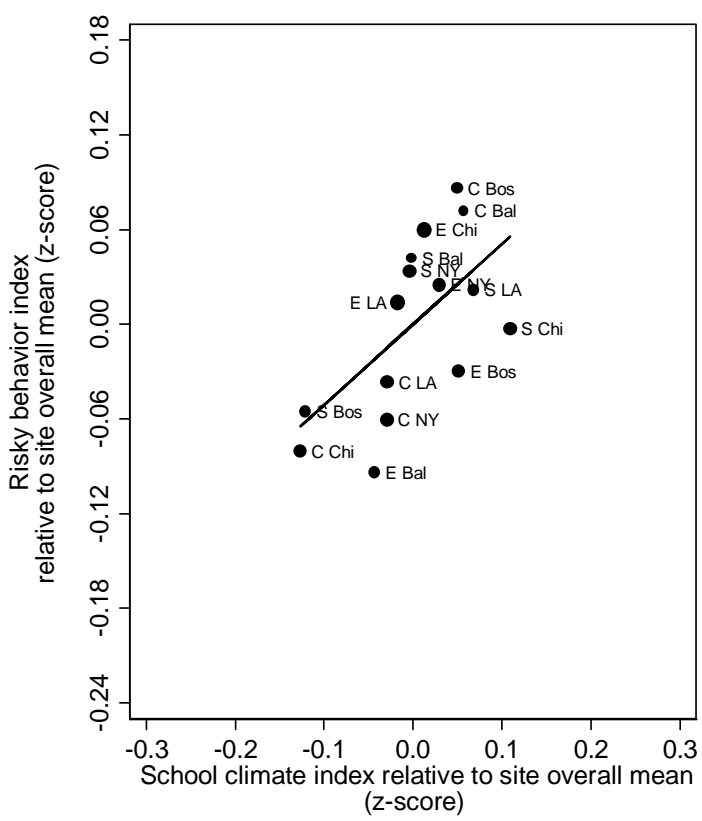

C

FEMALE YOUTH: Risky Behavior vs. School Climate Controlling for Poverty

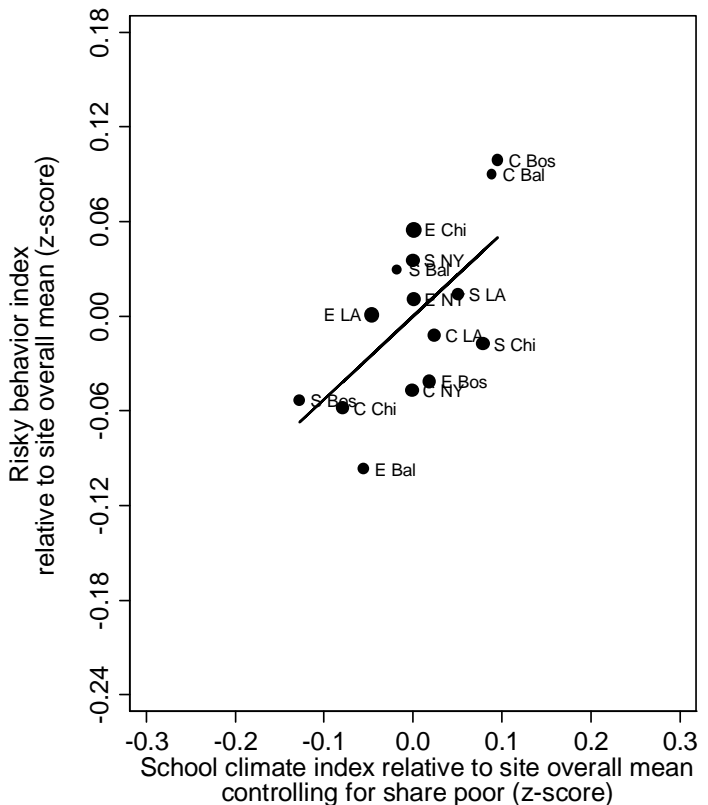

B

MALE YOUTH: Risky Behavior vs. School Climate

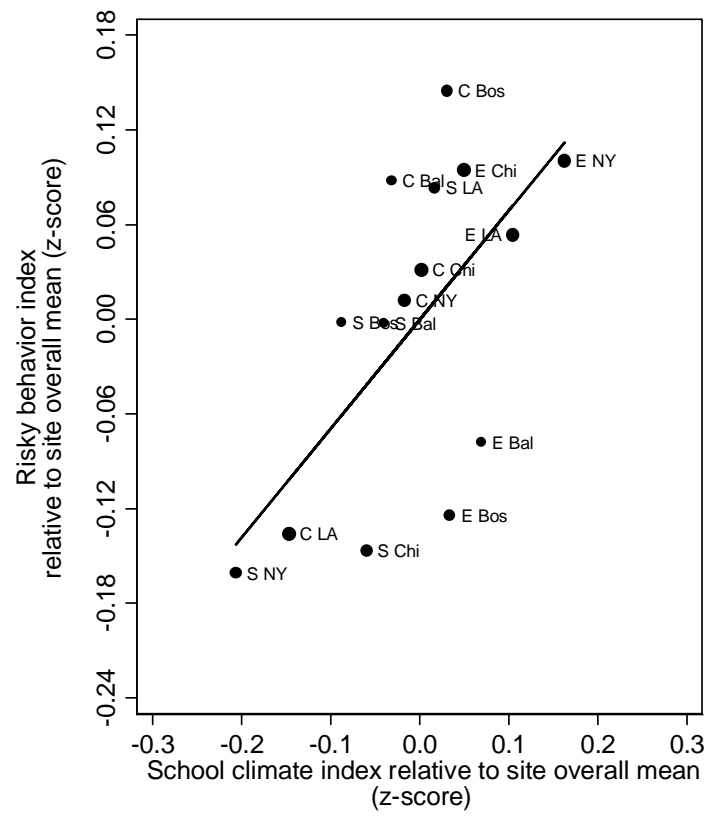

D

MALE YOUTH: Risky Behavior vs. School Climate Controlling for Poverty

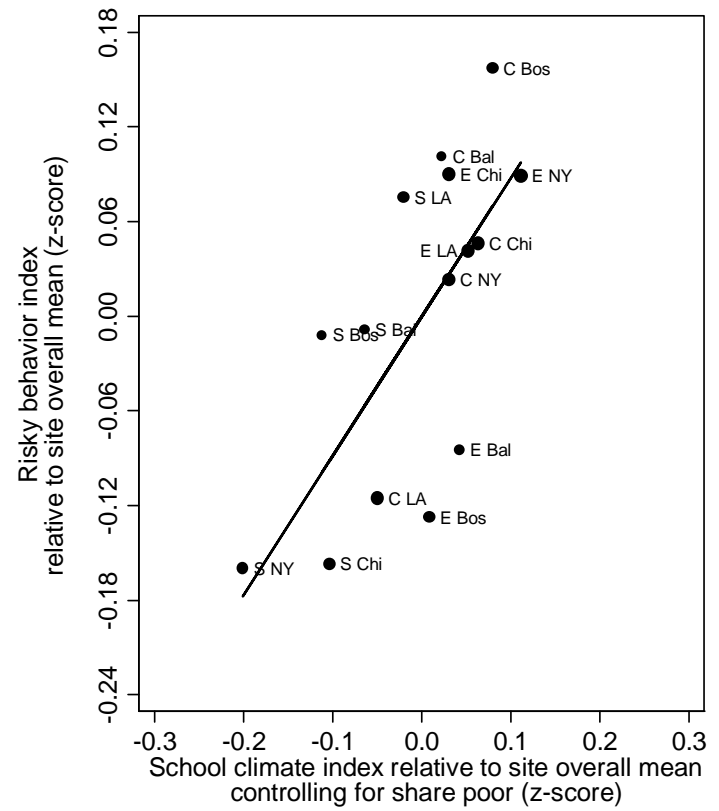


Notes to Appendix Figure 2: Instrumental variable estimation of the relationship between risky behavior and school climate for females (Panel A) and males (Panel B) and school climate controlling for poverty for females (Panel C) and males (Panel D). The y-axis is the risky behavior index expressed in standard deviation units relative to the sample control group standard deviation. The index has the following components: used marijuana in the past 30 days, smoked in the past 30 days, used alcohol in the past 30 days, and ever been pregnant or gotten someone pregnant. Each component was standardized using the mean and standard deviation for the control group. The index is the average of its components, restandardized using the control mean and standard deviation after averaging. Negative components were flipped so that higher index values represent "better" outcomes. School climate is the ratio of positive responses on five school quality items: safety, discipline, feeling "put down” by teachers, teasing of students who study hard, and teacher interest in students. Poverty (share poor), controlled for in panels C and $\mathrm{D}$, is the fraction of census tract residents living below the poverty threshold, linearly interpolated from the 1990 and 2000 decennial census and 2005-09 American Community Survey and weighted by the amount of time respondents lived at each of their addresses from random assignment through May 2008. School climate and share poor are expressed as z-scores standardized by the control group mean and standard deviation. The points represent the site $(\mathrm{Bal}=$ Baltimore, Bos = Boston, Chi $=$ Chicago, LA = Los Angeles, NY = New York City) and treatment group $(\mathrm{E}=$ Experimental voucher, $\mathrm{S}=$ Section 8 voucher, $\mathrm{C}=$ control group). The line through the data points is equivalent to a two-stage least-squares estimate of the relationship between risky behavior and school climate, using site-group interactions as instruments (conditional on site main effects). The size of each point is proportional to the sum of the weights for that group and, correspondingly, to the weight that the point receives in the two-stage least squares regression. The estimated impact of a 1 standard deviation (sd) improvement in school climate is a 0.512sd decrease in risky behavior for females (Panel A; N=2361, SE=0.434, $\mathrm{P}=0.239$ ) and a 0.691sd decrease for males (Panel $\mathrm{B}$; $\mathrm{N}=2267, \mathrm{SE}=0.266, \mathrm{P}=0.009$ ). When controlling for poverty, the estimated impact of a 1sd improvement in school climate is a 0.529sd decrease in risky behavior for females (Panel $\mathrm{C} ; \mathrm{N}=2358, \mathrm{SE}=0.441, \mathrm{P}=0.231$ ) and a 0.882sd decrease for males (Panel $\mathrm{D} ; \mathrm{N}=2263$, SE=0.348, $\mathrm{P}=0.011)$. 


\section{Appendix Figure 3}

\section{Instrumental Variable Estimation of the Relationship between Educational Attainment and School Rank}

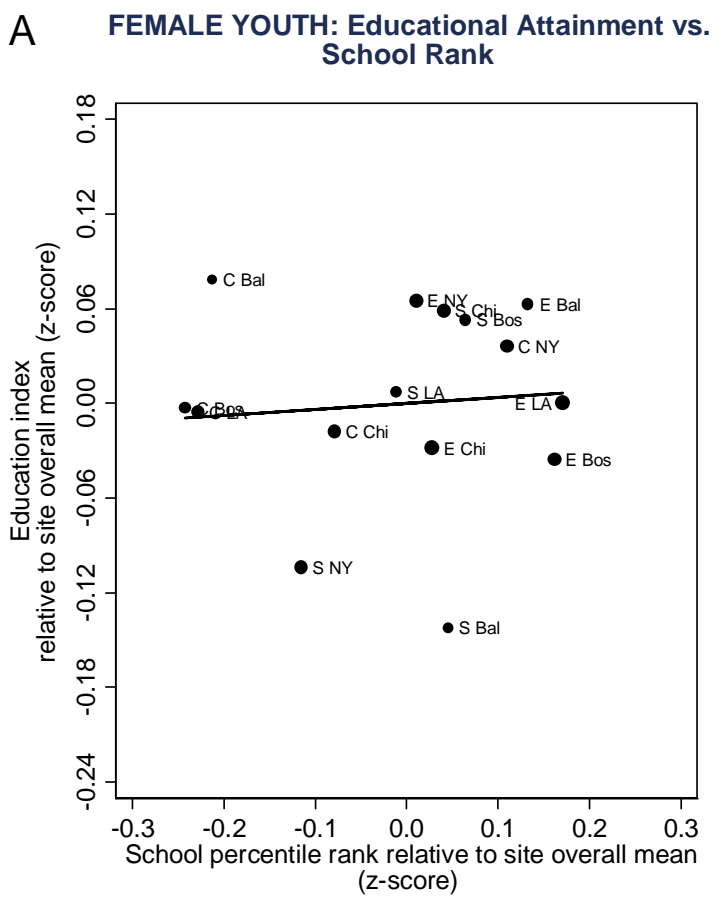

C FEMALE YOUTH: Educational Attainment vs. School Rank Controlling for Poverty

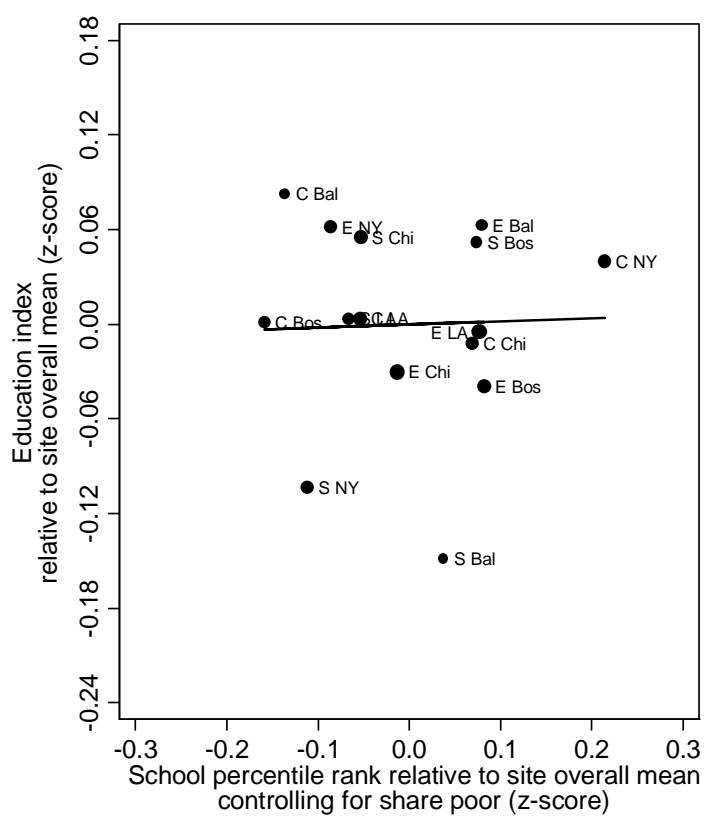

B MALE YOUTH: Educational Attainment vs. School Rank

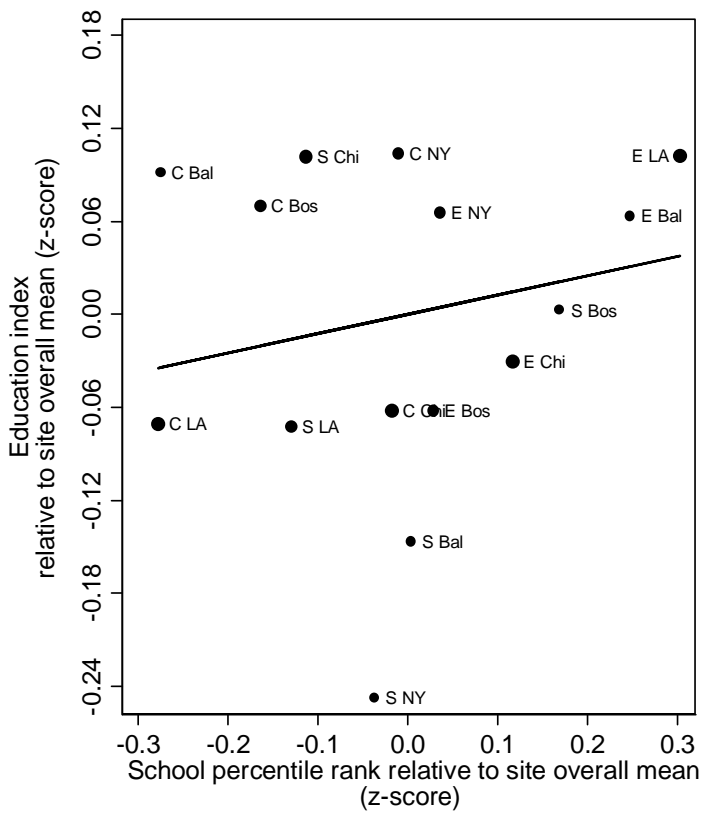

MALE YOUTH: Educational Attainment vs. School Rank Controlling for Poverty

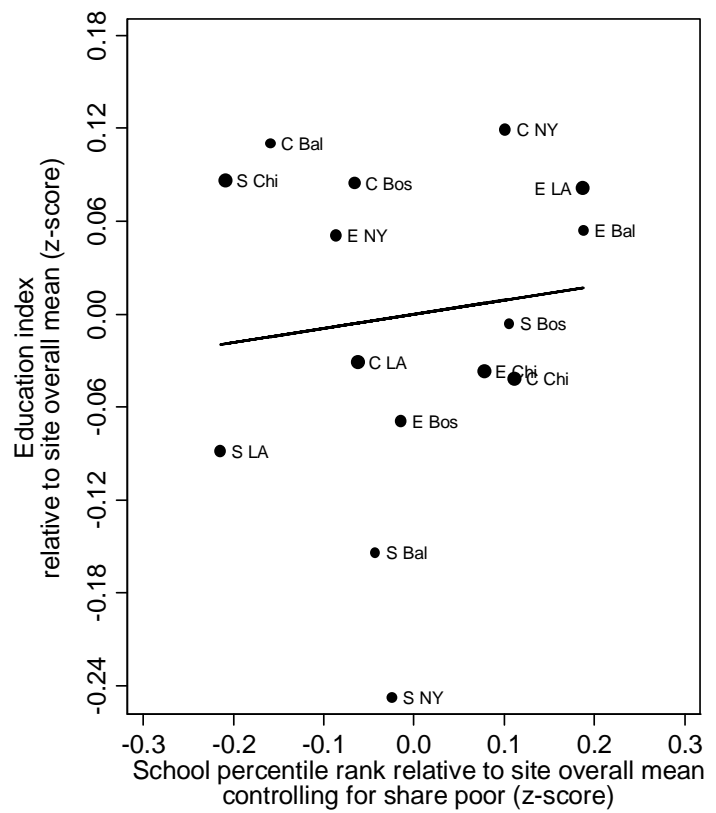


Notes to Appendix Figure 3: Instrumental variable estimation of the relationship between educational attainment and school rank for females (Panel A) and males (Panel B) and school rank controlling for poverty for females (Panel C) and males (Panel D). The y-axis is the education index expressed in standard deviation units relative to the sample control group standard deviation. The index has the following components: graduated high school/received certificate of General Educational Development (GED) or still in school, in school or working, ECLS-K reading score, and ECLS-K math score. Each component was standardized using the mean and standard deviation for the control group. The index is the average of its components, restandardized using the control mean and standard deviation after averaging. Negative components were flipped so that higher index values represent "better" outcomes. School rank is the percentile rank of the youth's average school (weighted by the number of years spent in each school) on state-level math and reading assessments. Poverty (share poor), controlled for in panels C and $\mathrm{D}$, is the fraction of census tract residents living below the poverty threshold, linearly interpolated from the 1990 and 2000 decennial census and 2005-09 American Community Survey and weighted by the amount of time respondents lived at each of their addresses from random assignment through May 2008. School rank and share poor are expressed as z-scores standardized by the control group mean and standard deviation. The points represent the site $(\mathrm{Bal}=$ Baltimore, Bos = Boston, Chi $=$ Chicago, LA $=$ Los Angeles, $\mathrm{NY}=$ New York City) and treatment group (E = Experimental voucher, $\mathrm{S}=$ Section 8 voucher, $\mathrm{C}=$ control group). The line through the data points is equivalent to a two-stage least-squares estimate of the relationship between educational attainment and school rank, using site-group interactions as instruments (conditional on site main effects). The size of each point is proportional to the sum of the weights for that group and, correspondingly, to the weight that the point receives in the two-stage least squares regression. The estimated impact of a 1 standard deviation (sd) increase in school rank is a 0.038sd increase in educational attainment for females (Panel A; $\mathrm{N}=2266, \mathrm{SE}=0.184, \mathrm{P}=0.837$ ) and a 0.125 sd increase for males (Panel B; $\mathrm{N}=2192$, $\mathrm{SE}=0.132, \mathrm{P}=0.344$ ). When controlling for poverty, the estimated impact of a 1sd increase in school rank is a 0.020sd increase in educational attainment for females (Panel C; $\mathrm{N}=2263$, SE=0.277, $\mathrm{P}=0.941$ ), and a 0.092sd increase for males (Panel $\mathrm{D}$; $\mathrm{N}=2188$, $\mathrm{SE}=0.188, \mathrm{P}=0.626)$. 


\section{Appendix Figure 4}

\section{Instrumental Variable Estimation of the Relationship between Risky Behavior and School Rank}

A

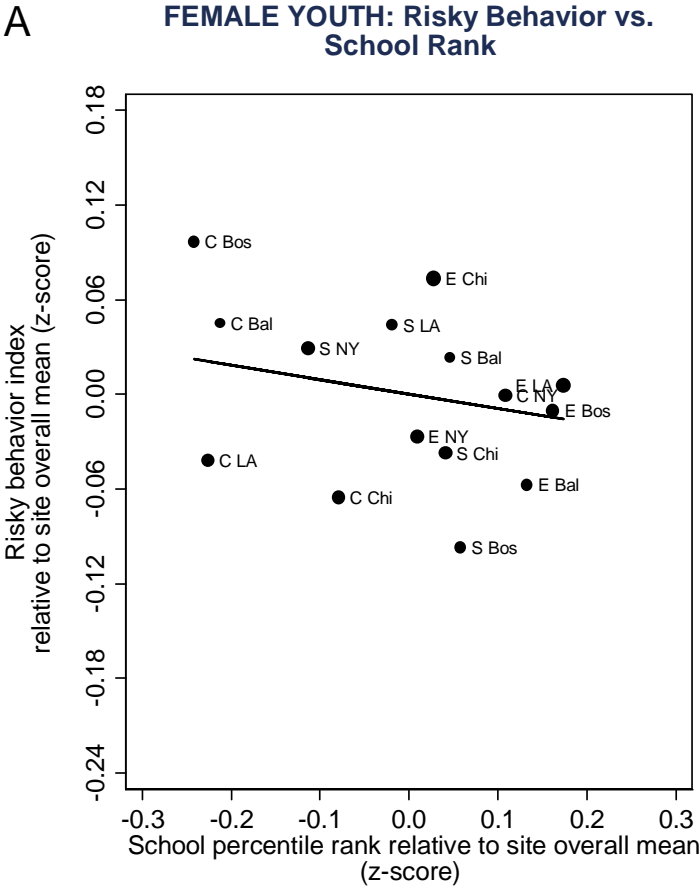

C

FEMALE YOUTH: Risky Behavior vs. School Rank Controlling for Poverty

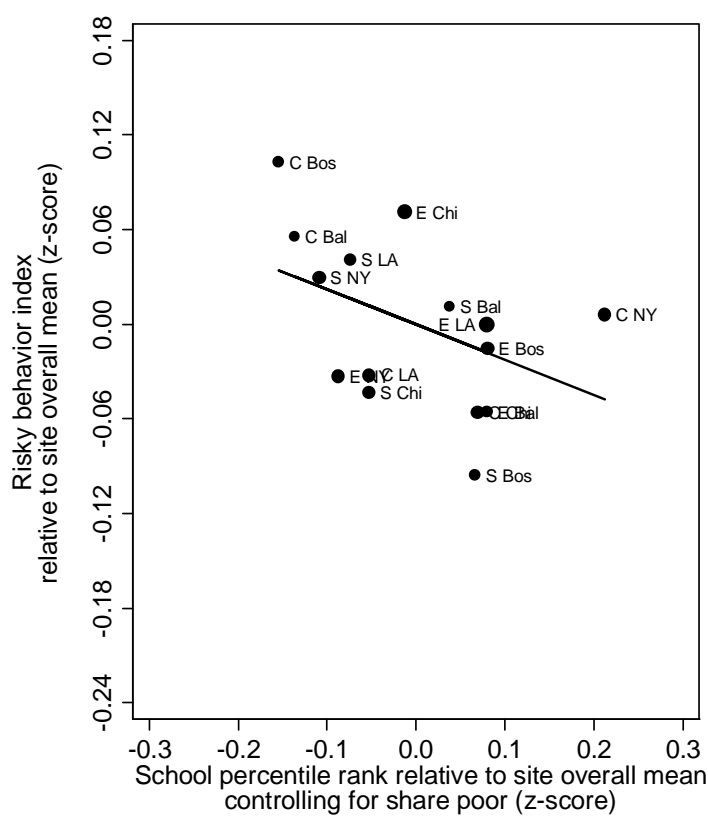

B

MALE YOUTH: Risky Behavior vs. School Rank

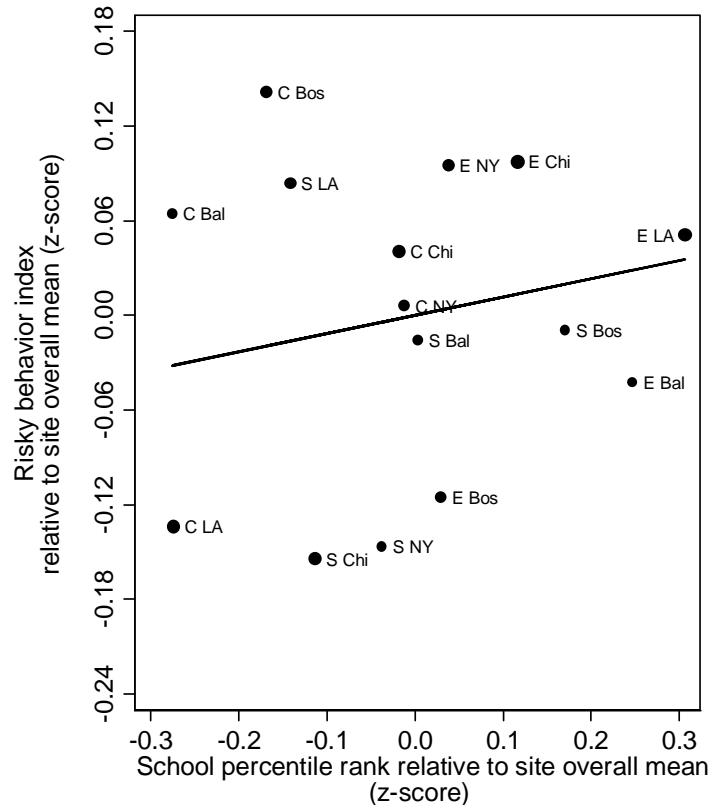

D

MALE YOUTH: Risky Behavior vs. School Rank Controlling for Poverty

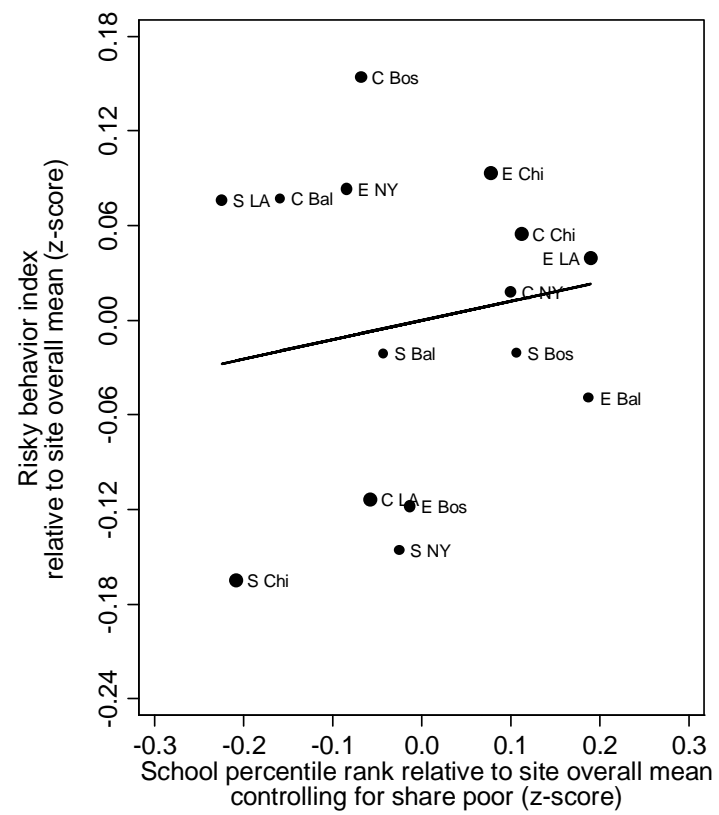


Notes to Appendix Figure 4: Appendix Figure 4. Instrumental variable estimation of the relationship between risky behavior and school rank for females (Panel A) and males (Panel B) and school rank controlling for poverty for females (Panel C) and males (Panel D). The y-axis is the risky behavior index expressed in standard deviation units relative to the sample control group standard deviation. The index has the following components: used marijuana in the past 30 days, smoked in the past 30 days, used alcohol in the past 30 days, and ever been pregnant or gotten someone pregnant. Each component was standardized using the mean and standard deviation for the control group. The index is the average of its components, restandardized using the control mean and standard deviation after averaging. Negative components were flipped so that higher index values represent "better" outcomes. School rank is the percentile rank of the youth's average school (weighted by the number of years spent in each school) on state-level math and reading assessments. Poverty (share poor), controlled for in panels C and D, is the fraction of census tract residents living below the poverty threshold, linearly interpolated from the 1990 and 2000 decennial census and 2005-09 American Community Survey and weighted by the amount of time respondents lived at each of their addresses from random assignment through May 2008. School rank and share poor are expressed as z-scores standardized by the control group mean and standard deviation. The points represent the site $(\mathrm{Bal}=$ Baltimore, Bos $=$ Boston, Chi $=$ Chicago, $\mathrm{LA}=$ Los Angeles, NY = New York City) and treatment group ( $\mathrm{E}=$ Experimental voucher, $\mathrm{S}=$ Section 8 voucher, $\mathrm{C}=$ control group). The line through the data points is equivalent to a two-stage least-squares estimate of the relationship between risky behavior and school rank, using site-group interactions as instruments (conditional on site main effects). The size of each point is proportional to the sum of the weights for that group and, correspondingly, to the weight that the point receives in the two-stage least squares regression. The estimated impact of a 1 standard deviation (sd) increase in school rank is a 0.092sd increase in risky behavior for females (Panel A; $\mathrm{N}=2260, \mathrm{SE}=0.175, \mathrm{P}=0.600$ ) and a 0.116sd decrease for males (Panel $\mathrm{B}$; $\mathrm{N}=2189, \mathrm{SE}=0.140, \mathrm{P}=0.408$ ). When controlling for poverty, the estimated impact of a 1sd increase in school rank is a 0.223sd increase in risky behavior for females (Panel C; $N=2257, S E=0.257, P=0.386$ ) and a 0.882sd decrease for males (Panel D; $\mathrm{N}=2263$, SE=0.348, $\mathrm{P}=0.011$ ). 
Appendix Figure 5

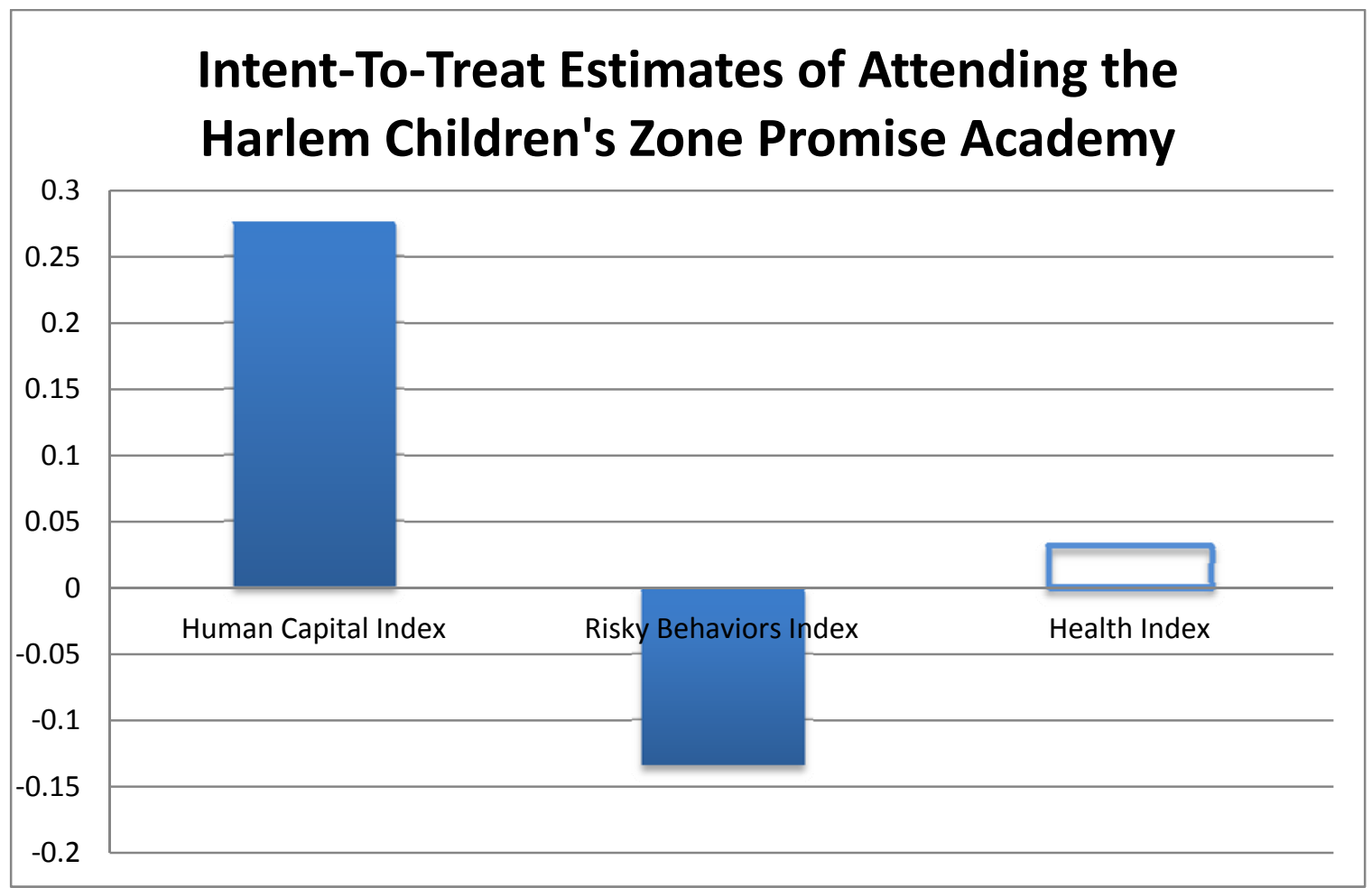

Notes to Appendix Figure 5: This figure reports the effects of winning the lottery to attend the Harlem Children's Zone Promise Academy reported by Dobbie and Fryer (2012). Each index is the average its subcomponents, after they were standardized using the mean and standard deviation in the control group. The human capital index has the following components: Woodcock Johnson Math, Woodcock Johnson Reading, number of high school Regents exams passed, average Regents score, and an indicator for enrolling in college. The risky behaviors index has the following components: ever pregnant (females only), incarcerated (males only), an index of drug and alcohol usage, and an index of criminal behaviors. The health index has the following components: mental health, an index of healthy eating, an index of physical health, and an index of health behaviors. See Dobbie and Fryer (2012) for more precise variable definitions. The effect of winning the Promise Academy lottery on human capital is 0.277 standard deviations ( $\mathrm{sd})(\mathrm{N}=552, \mathrm{SE}=0.068, \mathrm{P}=0.000)$. The effect on risky behaviors is $-0.135 \mathrm{sd}(\mathrm{N}=445$, $\mathrm{SE}=0.072, \mathrm{P}=0.063)$. The effect on health is $0.032 \mathrm{sd}(\mathrm{N}=407, \mathrm{SE}=0.057, \mathrm{P}=0.573)$. 